\title{
Evaluation of Impact Strength of Epoxy Based Hybrid Composites Reinforced with E-Glass/Kevlar 49
}

\author{
SUBHAN ALI JOGI*, MUHAMMAD MOAZAM BALOCH**, ALI DAD CHANDIO***, \\ IFTIKHAR AHMED MEMON*, AND GHULAM SARWAR CHANDIO**** \\ RECEIVED ON 18.01.2017 ACCEPTED ON 29.05.2017
}

\begin{abstract}
In hybridization different fibers are stacked layer by layer to produce laminates have specific strength and stiffness and employed in light weight high strength applications. Physically mean fabricated hybrid composites used in aerospace, under water, body armors and armed forces establishment. In present work drop-weight impact response of hybrid composites were investigated by making laminates of hybrid composites. In Hybridization layers of E-glass (roving) and Kevlar 49 fabrics stacked with epoxy resin. The layers formulation was set up by hand layup method. Impregnationsof epoxy resin of commercial grade (601A) in fabrics were accomplished by VRTM (Vacuum Bagging Resin Transfer Molding) technique. Layup placementof Glass fibers/ Kevlar at $0^{\circ} / 90^{\circ}, 45^{\circ} / 45^{\circ}$ and $30^{\circ} / 60^{\circ}$ were set for this work. Mechanical properties such as impact strength, bear resistance and break resistance were analyzed by usingASTM D-256 and D-3763 standard.Experimental investigation was conducted using instrumented Dart impact and Izod Impact test. E-glass/Kevlar 49 at layup $0^{\circ} / 90^{\circ}$ and $30^{\circ} / 60^{\circ}$ exhibited improvedimpact strength than $45^{\circ} / 45^{\circ}$. The surface morphology and fractography were also investigated by capturing different images of Specimens by using the SEM (Scanning Electron Microscopy). The fiberreinforcement and matrix fracture were also observed by using SEM.The SEM images suggest that epoxy resin tightly bonded with Kevlar fibers whereas Glass fibers were pulled out from laminations.
\end{abstract}

Key Words: Hybrid Composites, Bear Resistance, Break Resistance Glass/Kevlar Fiber Reinforced Composite, Vacuum Bagging Resin Transfer Molding, and Scanning Electron Microscopy.

\section{INTRODUCTION}

$\mathrm{H}$ igh strength aramid fibers placed as core materials in laminates for combination of strength and ductility. Hybrid composites known for their strength-to-weight ratio and ability to absorb energy when struck by bullet therefore used for making body armors for armed forces establishment. Aramid fibers have symmetricin their internal structure
(Zhu et. al. [1]). Aramid fibers extensively used in air craft design, boat hulls, sports goods and armed forces applications (Reis et. al. [2]). Kevlar fibers cross-linked with thermosetting resin to produced hardened product. Aramid fibers have specific strength and stiffness and incorporated matrix where toughness is required (Reis et. al. [3]). Layup placement and reinforcement fibers are 
effective tools for fabrication of hybrid composites. Eglass fibers have high tensile strength and placed out for making stiff sandwich structure (Alam et. al. [4]). For light weight high strength applications reinforcement of Kevlar fibers with glass fibers have significant achievement to fabricate low density materials having enhanced impact strength (Wang et. al. [5]). Impact strength of hybrid composites strongly depends upon the selection of reinforcement and layup placement. Kevlar fibers have inter- laminar fracture toughness and working as core material for effective hybridization.Hybrid composites are fabricated by stacking layers by layers with vacuum bagging resin transfer molding technique. Thickness of the laminate maintained at around 3-4mm according to ASTM standard (Reis et. al. [2]).Glass fiber reinforcement polymer has considerable application where light weight and high strength is required. Mechanical strength of composites material relies on the way of layup placement. The glass fibers as reinforcement materials are frequently used in aerospace and construction industries. Aramid fibers reinforcement polymers exhibit superior ultimate tensile strength, elastic modulusand impact energy (Reis et. al. [3]). Kevlar fiber of 5-7mm enhanced the delamination toughness. Kevlar fibers used as core material in lamination and improve the fracture toughness of the composite structures (Sohn et. al. [6]). Kevlar fibers have specific strength associated with failure mechanism and used in impact performance at low weight. Aim of present work is to discuss the experimental results obtained by changing angle ply orientation of reinforced materials. Impact properties of the materials are analyzedby calculating potential energy in joules by observing break and bear resistance of the materials using instrumented dart impact test. Izod impact test also conducted using izod impact tester to observe impact energy joules/meter.

\section{EXPERIMENTAL WORK}

\subsection{Specimen Fabrication}

Laminate of 9 layers $4 \mathrm{~mm}$ thick were fabricated at room temperature under pressure of 30-100 Psi. Fabrication process is shown in Fig. 1(a-d). Sheets are prepared with E-glass/epoxy and E-glass/Kevlar epoxy by hand layup technique. The vacuum bagging resin transfer molding technology was used in order to avoid air escape from the mold cavity and to improve the bonding of layers and matrix. Thermosetting resin is effective tool to improve the crosslinking between the thermoplastic and enhance the impact strength of the laminates. For specimen fabrication layup placement of $0^{\circ} / 90^{\circ}, 45^{\circ} / 45^{\circ}$ and $30^{\circ} / 60^{\circ}$ were selected. Finally, the laminate cured at room temperature for 24 hours, curing was performed to transform thermoplastic liquid into hardened product. Layup placement of hybrid composites is given in Table 1.

\section{DART IMPACTTEST}

Drop weight impact tester designed to calculate break and bear resistance of fibers reinforcement in polymers. The drop-dart test conducted with various loading conditionsat room temperature. The adjusted falling speed of impactor was $4.43 \mathrm{~m} / \mathrm{s}$ and 50 Joules of energy. Falling height in dart impact tester is $1000 \mathrm{~mm}$ and falling mass is in range from 510-550g (Fig. 2).

ASTM D-3763 standard specimens for dart impact test were in square shape measuring 2x2in. Impact energy in form of potential energy(joules)was calculated by using $\mathrm{PE}=\mathrm{mgh}$.

\section{$2.3 \quad$ Izod Impact Test}

Izod impact test measure the toughness of the materials. The Izod impact powerfully dependson size of the specimen being tested because number of imperfection acts as stress raisers and deduce the fracture toughness of the laminate.The Izod impact test was conducted by selecting different specimens and these specimens were designedas per ASTM D-256 standard. The dimension of the specimens were $6.4 \times 12.7 \times 3.2 \mathrm{~mm}$ and radius of the notch was $0.25 \mathrm{R}$ havingnotch lengthof 2mm (Fig. 3 and Fig. 4 (a-d)).

\section{SCANNING ELECTRONIC MICROSCOPY}

Izod impact test specimens were selected for SEM. Abrasive disc (V101) cutter was used to separate the fracture zone. As received samples were investigated to analyze the angle ply orientation and surface morphology.SEM images with various magnifications were selected by using $5 \mathrm{KV}$ secondary beam electrons. Experimental results such as

Mehran University Research Journal of Engineering \& Technology, Volume 36, No. 4, October, 2017 [p-ISSN: 0254-7821, e-ISSN: 2413-7219] 
matrix fiberbond strength, fracture of laminate and arrangements fibers were evaluated by using scanning electronic microscopy (Fig. 5).

\section{RESULT AND DISCUSSION}

The load bearing capacity of hybrid laminates were characterizedby using Dart Impact Test. Specimens was

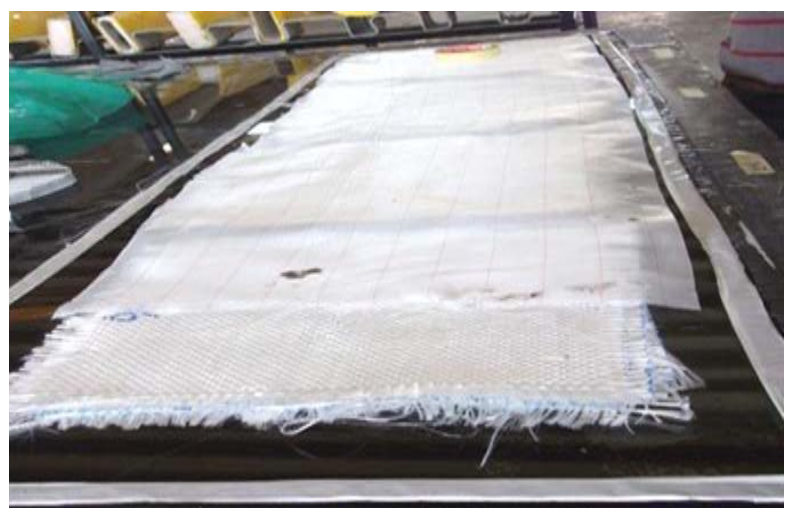

(a) PEEL PLY PLACEMENT

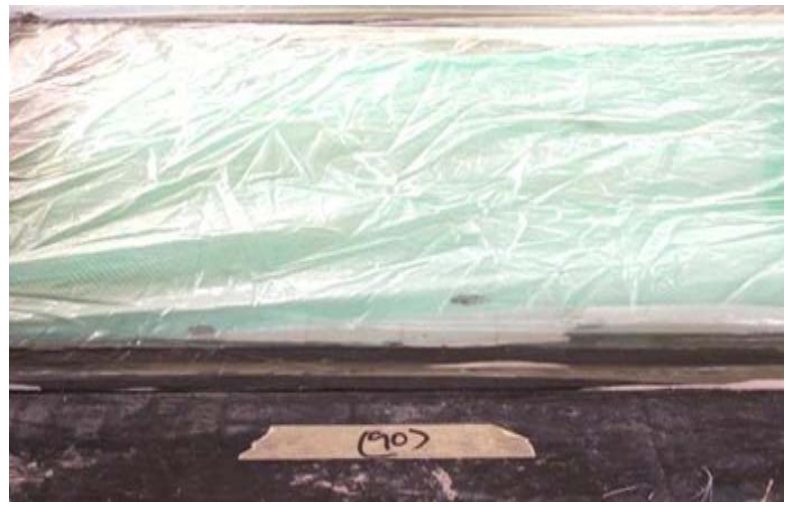

(c) BAGGING FOR GF $0 \% 90$ tested with different angle ply orientation, their resistances to penetration were observed by analyzing bear and break resistance.Considerable data have been generated regarding the bear and break resistance mentioned in the bar graph shown in Fig. 6 at GF $0^{\circ} / 90^{\circ}$ and GFK $0^{\circ} / 90^{\circ}, 45^{\circ} \%$ $45^{\circ}$ and $30^{\circ} / 60^{\circ}$.

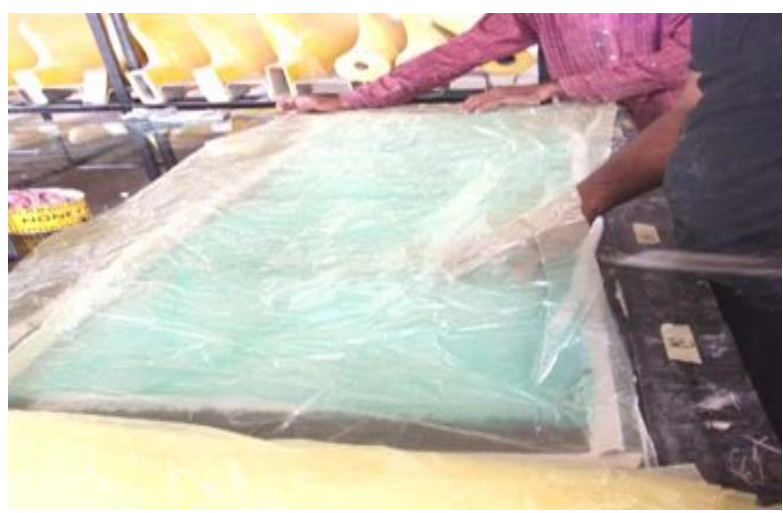

(b) BAGGING WITH SEALING TAP



(d) RESIN TRANSFER

FIG. 1. VRTM PROCESS

TABLE 1. LAYUP PLACEMENT WITH DIFFERENT ORIENTATION

\begin{tabular}{|c|c|c|c|c|c|}
\hline $\begin{array}{c}\text { Layers } \\
\text { Formation }\end{array}$ & Layers & $\begin{array}{c}\text { Layers of Glass Fiber } \\
\text { (Roving) }\end{array}$ & $\begin{array}{c}\text { Layers of Kevlar } \\
\text { Fibers 49 }\end{array}$ & $\begin{array}{c}\text { Angle of } \\
\text { Orientation GF }\end{array}$ & $\begin{array}{c}\text { Angle of } \\
\text { Orientation of KF }\end{array}$ \\
\hline A & 09 & 09 & - & $\left.0^{\circ} / 90^{\circ}\right)$ & - \\
\hline B & 09 & 05 & 04 & $30^{\circ}$ & $90^{\circ}$ \\
\hline C & 09 & 05 & 04 & $45^{\circ}$ & $60^{\circ}$ \\
\hline D & 09 & 05 & & & $45^{\circ}$ \\
\hline
\end{tabular}

Mehran University Research Journal of Engineering \& Technology, Volume 36, No. 4, October, 2017 [p-ISSN: 0254-7821, e-ISSN: 2413-7219] 
The recorded results of bear and break resistance of glass fiber-reinforced epoxy at $0 \% 90$ and glass/Kevlar fibers -reinforced epoxy at $0^{\circ} / 90^{\circ}, 45^{\circ} / 45^{\circ}$ and $30^{\circ} / 60^{\circ}$ were found to be $7.40,11.11,18.52,21.01,9.87,12.34,17.28$ and 19.75J respectively.The obtained results of several orientations have conformity with results reported by Babu et. al. [7]) and Rajesh at. al. [8]), that experiments were conducted by designing 11 layers laminate composite as compared to our 9 layers laminate composite. The experimental results of impact energy ( $\mathrm{J}$ ) were carried by the study of different specimens. Bar graph in Fig. 6 shows variation in databy change in layup placementof laminates. Hybrid composite Sheet of GFK at $0^{\circ} / 90^{\circ}$ has

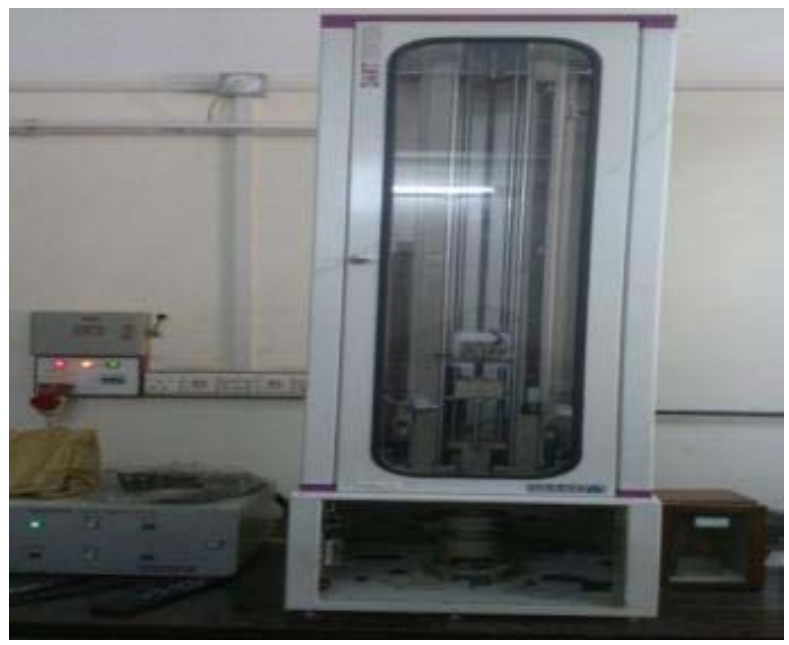

FIG. 2.DART IMPACT TESTER



FIG. 3. IZOD IMPACT TESTERS remarkable performance under loading conditions of dartdart. The GFK at $0^{\circ} / 90^{\circ}$ and $30^{\circ} / 60^{\circ}$ have highenergy absorption capacity then $45^{\circ} / 45^{\circ}$ orientation. It can also be analyzed from the reported results that bearand break resistance of glass fibers-Kevlar at angle ply $0 \% 190^{\circ}$ was $46.71 \%$ greater than $45^{\circ} / 45^{\circ}$ layup placement and $6.71 \%$ better than $30^{\circ} / 60^{\circ}$ orientation. It is also be studied that impact energy ofglass fibers-reinforced epoxy at $0^{\circ} / 90^{\circ}$ has less energy results fromglass fibers-Kevlarreinforced epoxy at $45^{\circ} / 45^{\circ}$ placement. Fig. 6 shows that GF-reinforced epoxy has low energy absorption than other layup placement. Fig. 7(a-d) shows the fracture specimen at different layup placement.

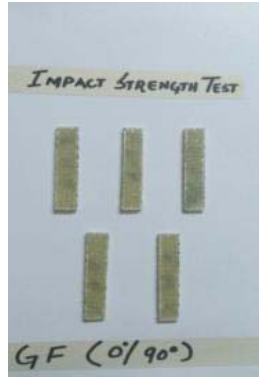

(A) $G F 0^{\circ} / 90^{\circ}$

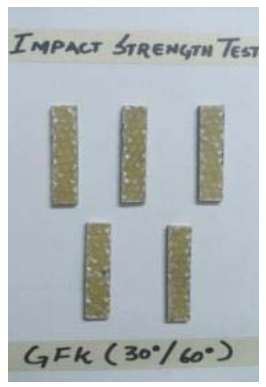

(C) GFK $30^{\circ} / 60$

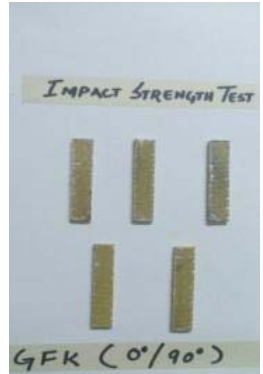

(B) $\mathrm{GFK} 0 \% 90$

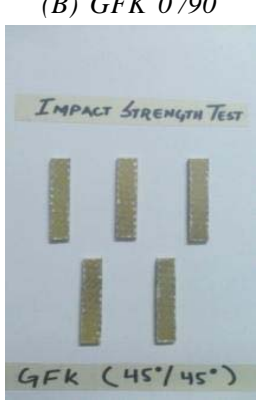

(D) $G F K 45^{\circ} / 45^{\circ}$
FIG.4. SPECIMENS WITH DIFFERENT ORIENTATIONS



FIG.5. JEOL JSM-6390A (SEM)

Mehran University Research Journal of Engineering \& Technology, Volume 36, No. 4, October, 2017 [p-ISSN: 0254-7821, e-ISSN: 2413-7219] 1012 
Fig. 8 shows variation of impact strength by different layup placement of glass fiber/epoxy and glass/Kevlar epoxy. Some difference in impact strength between the hybrids composites can be seen from the graph given in Fig. 8. Fig. 8 presents that glass-Kevlar bonded with epoxy at $0^{\circ} / 90^{\circ}, 45^{\circ} / 45^{\circ}$ and $30^{\circ} / 60^{\circ}$ layup placement exhibits upgrade impact strength compared with glass fiber jointed with epoxy at $0^{\circ} / 90^{\circ}$. The computed impact strength of GFK $0^{\circ} / 90^{\circ}$ is $7.6 \%$ greater than GFK $45^{\circ} / 45^{\circ}$.If impact strength of GFK $0^{\circ} / 90^{\circ}$ compared with GFK $30^{\circ} / 60^{\circ}$, it's computed value was $10.47 \%$ higher than GFK $30^{\circ} / 60^{\circ}$. Same finding were reported in literature of Alam et. al. [4]) and Valena et.al. [9]). By the understanding of bar graph in Fig. 8 shows that change in fibers orientation does not effective in enhancement of impact strength of hybrid laminates but replacement of fibers is useful for the improvement hybrid composites.

\subsection{Scanning Electronic Microscopy}

For the fabrication of hybrid laminate aramid fibers 49/glass fibers reinforcedepoxy at different layup placement were considered for study. Aramid fiber has in-plane impact strength and placed in core for making sandwich structure. Aramid fiber has trade name Kevlar is effective tool to suppress the specific strength and stiffness. Kevlar fiber has resistance to penetration and bonding capability and used in civil and military establishment for making the

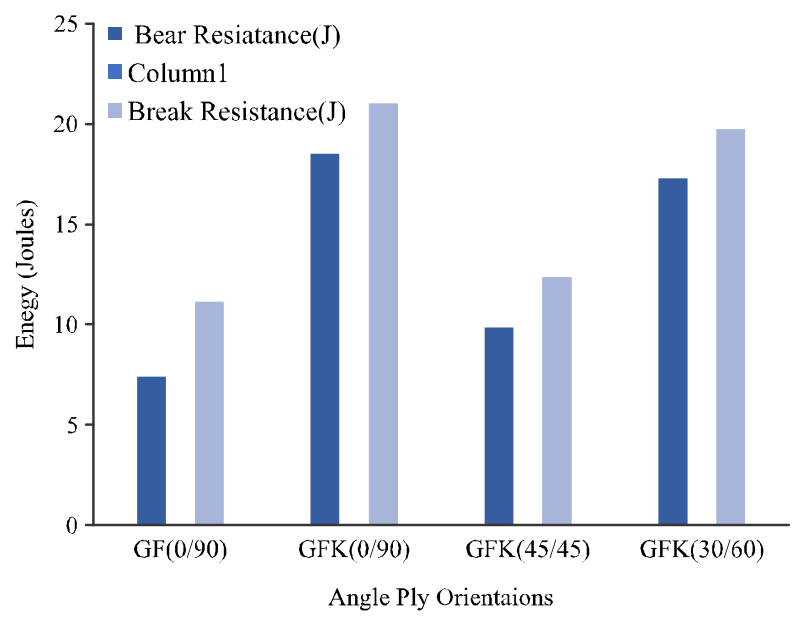

FIG. 6. BAR GRAPH SHOWS THE BEAR AND BREAK RESISTANCE CHARACTERISTICS OF GFO $/ 90^{\circ}$ AND GFK $0^{\circ} / 90^{\circ}, 45^{\circ} / 45^{\circ}$ AND $30^{\circ} / 60^{\circ}$

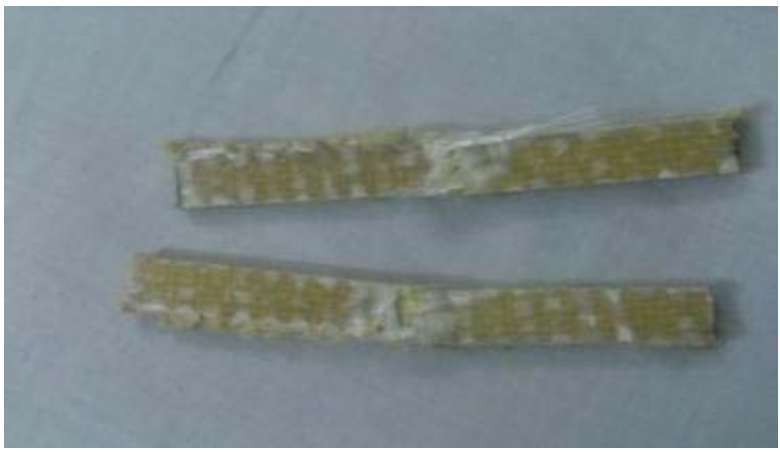

(a) GLASS/KEVLAR-REINFORCED EPOXY $0^{\circ} / 90^{\circ}$

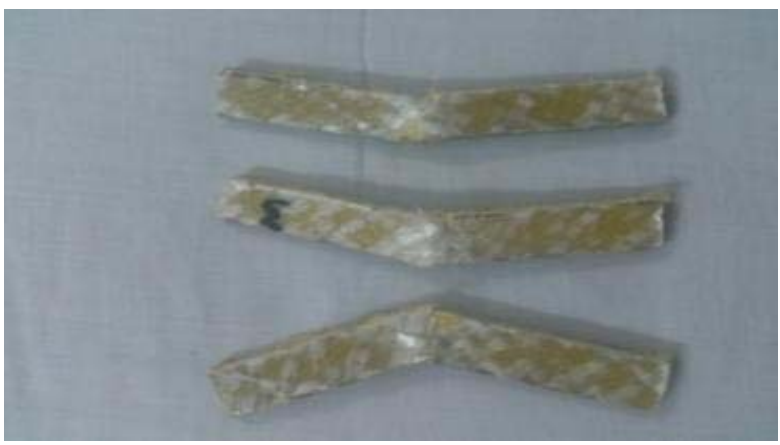

(b) GLASS/KEVLAR-REINFORCED EPOXY 30\%60

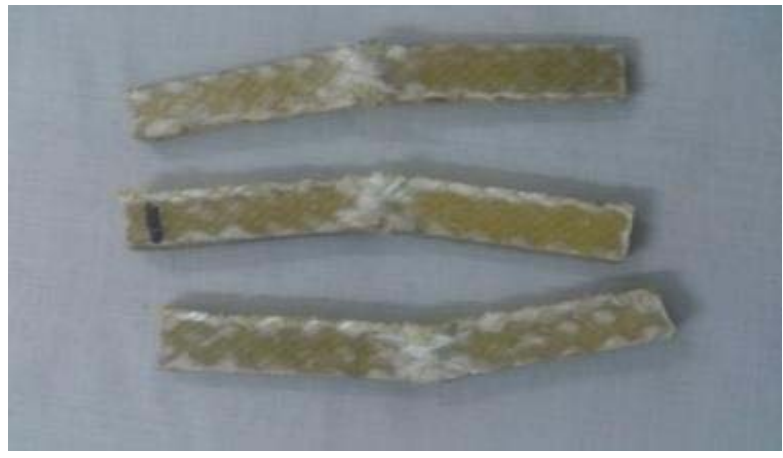

(c) GLASS/KEVLAR-REINFORCED EPOXY 45\% $45^{\circ}$

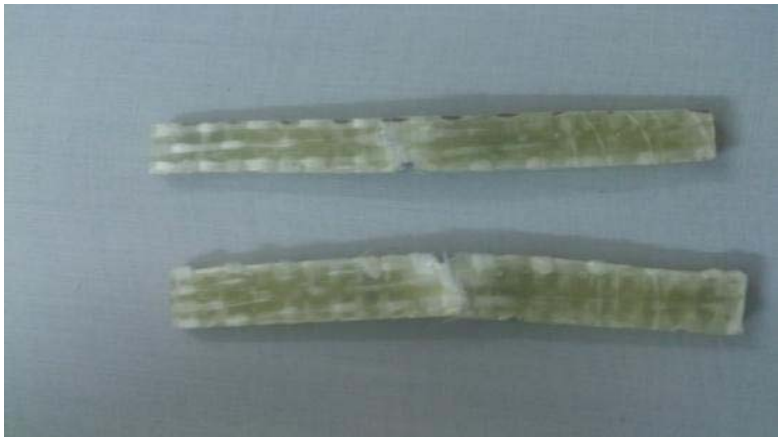

(d) GLASS-REINFORCED EPOXY $0^{\circ} / 90^{\circ}$

FIG. 7. SPECIMEN AFTER FRACTURE

Mehran University Research Journal of Engineering \& Technology, Volume 36, No. 4, October, 2017 [p-ISSN: 0254-7821, e-ISSN: 2413-7219] 
components parts (Reis et. al. [3]). The scanning electronic microscopy discovered the layup placement and fractography of laminate. Fig.9identified the epoxy resin bonded with glass fibers at $0^{\circ} / 90^{\circ}$ before fracture.

The cross-sectional view of glass fibers-reinforced epoxy was seen in Fig. 9 at $0 \% 90$ orientations The solution of epoxy resin and hardener were placed between the layers of hybrid composites laminate. Fig. 9 shows perfect sequential layers of glass fibers adhesive with epoxy.

Pictorial view of GF $0^{\circ} / 90^{\circ}$ shows delimitation was taken place at the centre of impact zone. Impact strength of laminates was reduced by pull out the glass fibers from the sandwich structure by minimum energy absorptions. The placement of layers at different angles were not increase the impact energy of composites but selection fibers in hybridization is very important to enhance the impact strength. Izod tested specimens of GFK $0^{\circ} / 90^{\circ}$ have

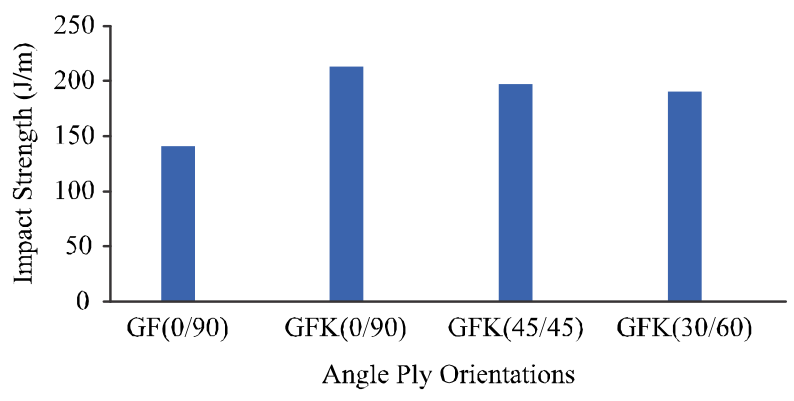

FIG.8.BAR GRAPH SHOWS IMPACT STRENGTH GLASS FIBERS-REINFORCED EPOXY AT $0^{\circ} / 90^{\circ}$ AND GLASS/ KEVLAR -REINFORCED EPOXY AT VARIOUS ANGLES

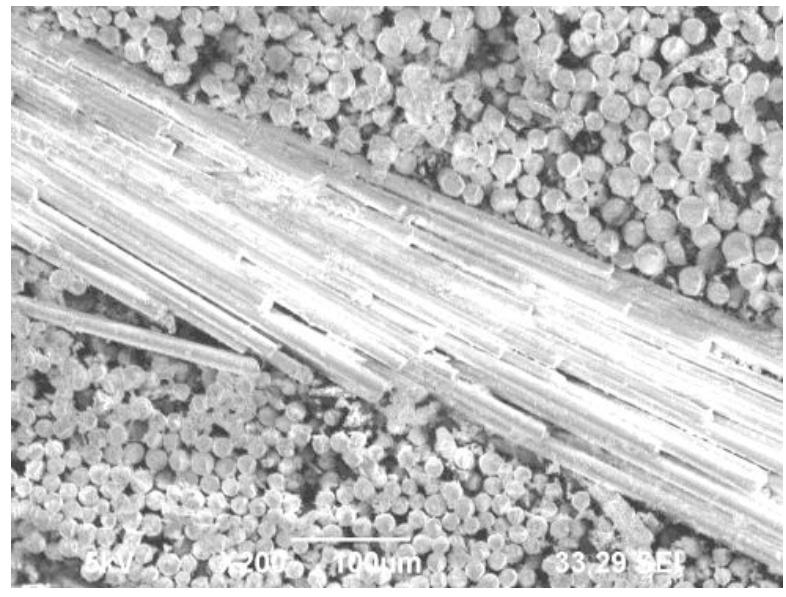

FIG. 9. IDENTIFICATIONOF LAYUP PLACEMENT OF GLASS FIBERS REINFORCED EPOXY AT $0^{\circ} / 90^{\circ}$ BEFORE FRACTURE maximum impact strengththan glass fiber - reinforced epoxy at same layup placement, similardata were calculated by Reis et.al. [2]) Fig. 10.

Nine layers of glass fiber-Kevlar at $0^{\circ} / 90^{\circ}$ were seen in images of scanning electronic microscope. Five alternating layers of glass fibers and four layers of aramid fibers placed in sequence stacked layer by layer by epoxy were shown Fig. 11. Selected micrograph at different magnification reported that Kevlar adhesive with epoxy whereas some glass fibers were delaminated from hybrid composites. Young's modulus of laminates relies on fiber reinforced epoxy. The proper use of fibers improves the mechanical strength of hybrid laminates. Similar findings were also reported by number of researchers Satish et. al. [10]) and Reis et. al. [2]). In order to understand the inplane fracture toughness, hybrid compositesstrongly depends on fibers matrix bond strength and selection of fibers. The finding from experimental data is good agreement with literature.

SEM micrograph in Fig. 12 shows that Kevlar fibers bonded with epoxy, whereas the glass fibers deboned from the hybrid laminates. By the investigation of image given in the Fig. 13 it was understood that impact strength of hybrid composites depend son way of layup placement. By insightful of experimental results at $0^{\circ} / 90^{\circ}, 45^{\circ} / 45^{\circ}$ and $30^{\circ} / 60^{\circ}$ it was observed that that fibers orientation $0^{\circ} / 90^{\circ}$ have better impact strength and stiffness.



FIG. 10. FRACTURE OF SPECIMEN GF -REINFORCED EPOXY AT $0^{\circ} / 90^{\circ}$

Mehran University Research Journal of Engineering \& Technology, Volume 36, No. 4, October, 2017 [p-ISSN: 0254-7821, e-ISSN: 2413-7219] 
Fig. 14 shows way of placing the fibers at $30^{\circ} / 60^{\circ}$ layup for making the laminate. The surface morphology of hybrid composites clearly shows the direction of fibers reinforced epoxy. By the study of SEM images of Izod test specimen it was clear that at $0^{\circ} / 90^{\circ}$ orientation have higher Impact energy then $45^{\circ} / 45^{\circ}$ and $30^{\circ} / 60^{\circ}$. In specimen where fibers orientated at $45^{\circ} / 45^{\circ}$ and $30^{\circ} / 60^{\circ}$ direction has variation in results, fibers are broken and pulling out from the laminationsbecause of stress concentration. In case of $0^{\circ} / 90^{\circ}$ fibers are bonded with epoxy because fibers arranged parallel to the load directions. The layup placement of fibers reinforced in matrix at $45^{\circ} / 45^{\circ}$ and $30 \% 60^{\circ}$ have specific strength and elongation. Fig.14 indicated that fibers are pulled out because the delimitation and failure laminate with single blow.

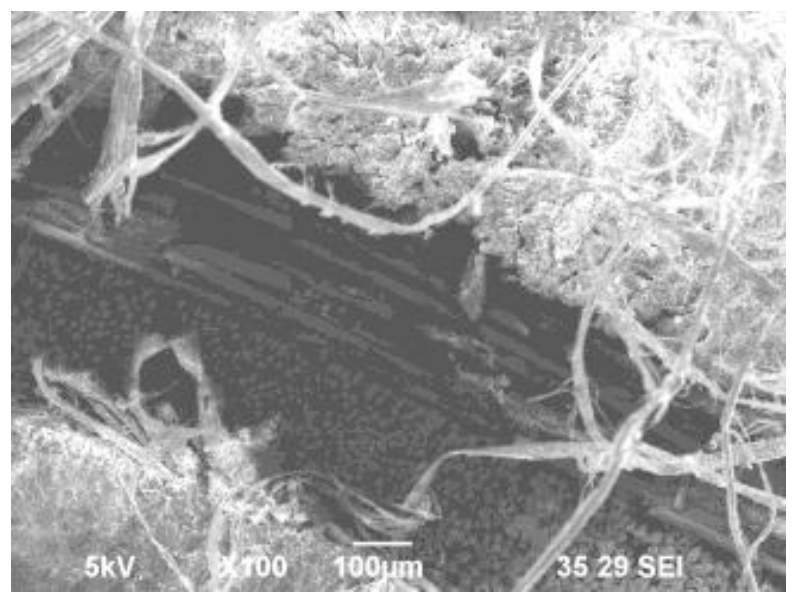

FIG.11. SHOWS NINE LAYERS OF GFK AT $0^{\circ} / 90^{\circ}$ BEFORE FRACTURE

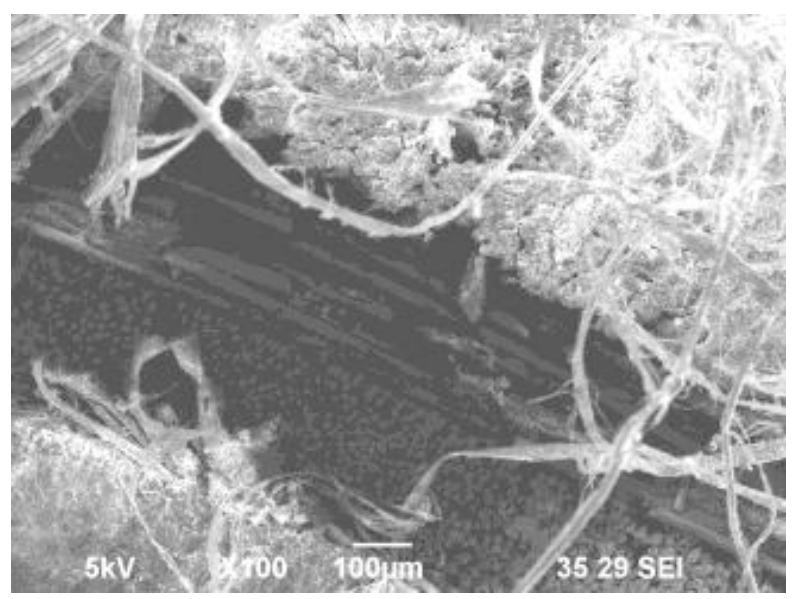

FIG. 12. FRACTURED SEM IMAGE OF GFK AT $0^{\circ} / 90^{\circ}$
Fig. 15 represents the nine layers of glass and Kevlar fibers adhesive with epoxy. In $45^{\circ} / 45^{\circ}$, placement the glass fibers pasted out from laminates during the sectioning by abrasive wheel cutter. From the surface study of $45^{\circ} \%$ $45^{\circ}$ direction it was observed the bonding strength of fibers depends also upon the fiber layup and proper selection of for fibers in laminations. Composites are physically mixed and their properties are based on layup placement fibers and adhesion fibers with matrix. The placement of fibers at $0^{\circ} / 90^{\circ}$ has bonding strength than $45^{\circ} / 45^{\circ}$ and $30^{\circ} / 60^{\circ}$. The layup placement $45^{\circ} / 45^{\circ}$ superior over $0^{\circ} / 90^{\circ}$ and $30^{\circ} / 60^{\circ}$ have force per unit area at fracture.

Pictorial view given in Fig. 16 shows the delimitation after complete pulling out of fibers are because of increase of stress concentration and specimen were failed by minimum energy absorption.

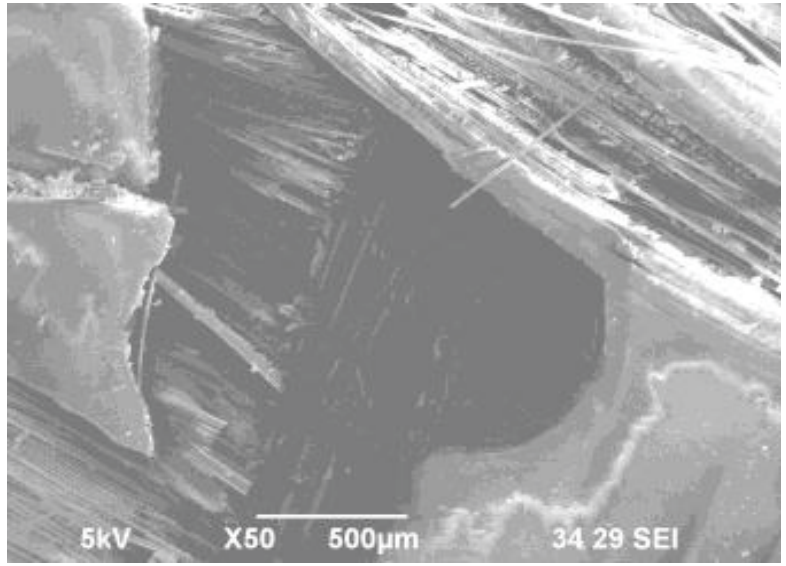

FIG. 14. SEM MICROGRAPH OF GFK30 $/ 60^{\circ}$ AT FRACTURE

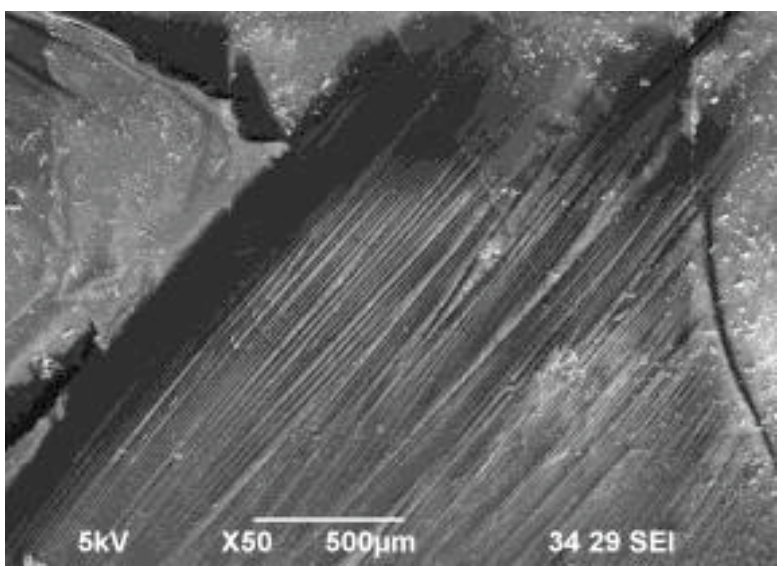

FIG. 13. SEM IMAGES OF GFK $30^{\circ} / 60^{\circ}$ AT LAYUP PLACEMENT

Mehran University Research Journal of Engineering \& Technology, Volume 36, No. 4, October, 2017 [p-ISSN: 0254-7821, e-ISSN: 2413-7219] 


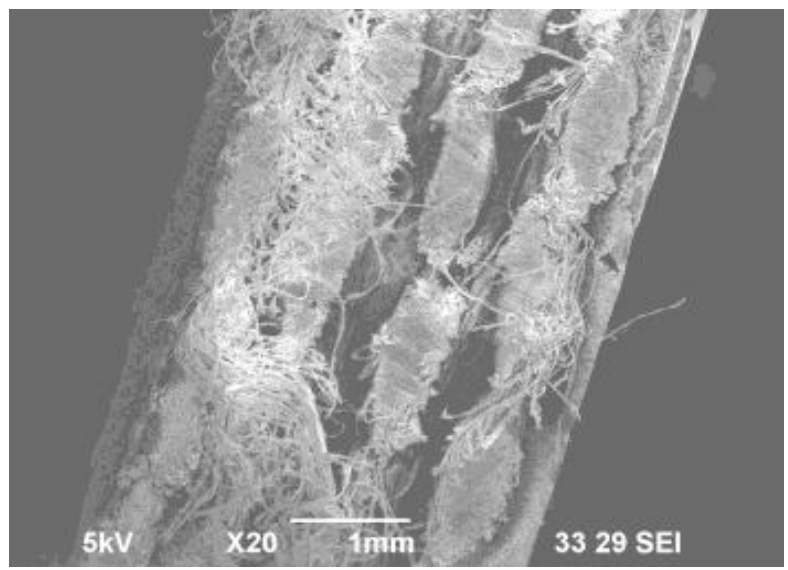

FIG. 15. MICROGRAPH OF GFK AT $45^{\circ} / 45^{\circ}$ BEFORE FRACTURE



FIG. 16. IMAGE OF GFK $45^{\circ} / 45^{\circ}$ AFTER FRACTURE

\section{CONCLUSION}

Experimental investigations were conducted to enhance the impact toughness of glass/epoxy and glass/Kevlar epoxy composites. From Dart impact test it was concluded that orientation GFK $0^{\circ} / 90^{\circ}$ and $30^{\circ} / 60^{\circ}$ have improved impact toughness than $45^{\circ} / 45$ whereas GF $0^{\circ} / 90^{\circ}$ have lowest value. But the surface and fracture study suggest that at $0^{\circ} / 90^{\circ}$ orientation has better fracture strength than other orientations. Therefore, it can concluded that best results can be obtained for designing the structures at $0 \% 90^{\circ}$ layup placement but as far as specific strength is concern angle ply orientation $45^{\circ} / 45^{\circ}$ is suitable.

\section{ACKNOWLEDGEMENT}

This paper best supported by SUPARCO under the supervision of Anwar Ghyio,Project Director and well supported by PCSIR, Karachi, and Dawood University of Engineering \& Technology, Karachi, Pakistan, in conduction of practical work.

\section{REFERENCES}

[1] Zhu, D., Mobashar, B., and Rajan, S D., "Dynamic Tensile Testing of Kevlar 49 Fabrics", Journal of Materials in CivilEngineering, Volume, 23, pp. 1-10, 2011.

[2] Reis, P.N.B., Ferreira, J.A.M., Zhang, Z.Y., Benameur, T., and Richardson, M.O.V., "Impact Response of Kevlar Composites with Nanoclay Enhanced Epoxy Matrix”, Journal on Composites, Part-B, Volume 46, pp. 7-14, 2013.

[3] Reis, P.N.B., Ferreira, J.A.M.,Santos, P., Richardson, M.O.W., and Santos, J.B., "Impact Response of Kevlar Composites with Filled Epoxy Matrix", Journal on Composite Structures, Volume 94, pp. 3520-3528, 2012.

[4] Alam, S., Habib, F., Irfan,M., Iqbal, W., and Khalid, K., "Effect of Orientation of Glass Fiber on Mechanical Properties of GRP Composites”, Journal of Chemistry Society Pakistan, Volume 32, pp. 265-269, 2010.

[5] Wang, H.W., Zhou, H.W., Gui, L.L.,Ji, H.W., and Zhang, X.C., "Analysis of Effect of Fiber Orientation on Young's Modulus for Unidirectional Fiber Reinforced Composite", InternationalJournal of Composites, Part-B, Volume 56,pp.733-749,2014.

[6] Sohn, M.S., Hu, X.Z., Kim, J.K., and Walker, L., "Impact Damage Characterization of Carbon Fiber/Epoxy Composites with Multi-Layer Reinforcement”, International Journal of Composite, Part-B, Volume 31, pp. 681-691,2000.

[7] Babu, S.L., and Shivanand, "Impact Analysis Laminated Composites on Glass Fiber and Carbon Fiber", International Journal of Emerging Technology \& Advanced Engineering, Volume 4, pp. 824-829,2014.

[8] Rajesh, N., and Jerald, M.J., "Experimental Investigation of Woven E-Glass Epoxy Composite Laminates Subjected to Low-Velocity Impact at Different Energy Levels”, Journal of Minerals \& Materials Characterization of Engineering, Volume 9, No. 7, pp. 643-652,2010.

[9] Valena, S.L., Griza, S., Gomes de Oliveira, V., Midori Sussuchi, E., and Carvalho de Cunha, F.G., " Evaluation of Mechanical behavior of Epoxy Composites Reinforced with Kevlar Plain Fabric and Glass/Kevlar Hybrid Fabric”, Journal of Composites, Part-B, Volume 70, pp. 1-8, 2015.

[10] Satish, K.G., Siddeswarappa, B., and Mohamed K.K., "Characterization of In-Plane Mechanical Properties of Laminated Hybrid Composites", Journal of Minerals \& Materials Characterization of Engineering, Volume 9, No. 2, pp. 105-114, 2010. 